\title{
Is the Smart Defense Concept an Innovation?
}

\section{Venelin Georgiev*}

Center for Security and Defense Management in the Institute on Information and Communication Technologies, Bulgarian Academy of Sciences, Bulgaria

Discussed extensively and gained popularity the smart defense concept is often presented as an innovative approach to building defense capabilities of the member states of NATO. In general, this concept has high expectations to solve the difficulties associated with ensuring security in the Euro-Atlantic region in terms of austerity of resources in general and drastically shrinking defense budgets. Whether, and how, in fact, the concept of smart defense can be considered as innovation in the defense resources management is a complex issue enough, that can be broadly discussed.

If we accept the hypothesis that this concept actually is an innovation we need to find answers to some important questions. Let's start with the definition of the phenomenon of innovation assuming that innovation is any new idea that works. In this context the concept of smart defense itself cannot be seen as innovation because it meets only the first part of the given definition. By itself, the concept is a winner of the new idea, and thus it's close to an invention. To make innovation the concept should be implemented, and to give concrete results. As a conclusion we can say that innovations tend to all forms of realization of the concept of smart defense that have the characteristics given below.

To be an innovation the smart defense concept should have three main characteristics: an element of novelty, usefulness for a wide range of users, and cost effectiveness. In terms of novelty items should be noted that the main tools of smart defense, such as specialization, prioritization, cooperation, economies of scale, etc. no longer a novelty in the theory and practice of management of defense resources. Here it may be noted that all innovations are related to the time and place for their implementation. In this regard, the member states of NATO certainly can be distinguished by the degree of integration of the characteristics listed above in the scope of their policies and practices in defense. This fact allows us to say that if for one of them the smart defense can be seen as innovation, then for others it is a long practice, gave concrete results. As regards the other two parameters - useful for a wide range of users and cost-effectiveness, the concept of smart defense can be described as innovation. Of course, this approach should be individualized and specific in the evaluation of any form for the realization of this concept.

To prove the hypothesis of innovative aspect of the smart defense concept we should be in position to classify this type of innovation or to make taxonomy. In the most common theory the innovations could be divided into product, process, organizational and marketing. Obviously, for the individual entities the smart defense concept will be a different kind of innovation. As an example - for NATO as a strategic organization is a marketing innovation, which offers a new way to build the necessary defense capabilities, for a number of Member States the same concept may be a process innovation that is related to the creation and implementation of new processes for management resources for defense, and for another part of Member States the concept should be organizational innovation requiring new organizational structure to be able to reap the benefits of the concept. In summary it can be said that the concept of smart defenses may deem to be unambiguously classified as innovation in cases where it may even be defined as innovation.

It is interesting the object of the innovative process to be fined, i.e. the novelty that is the fundamental for the smart defense concept. In other words, what is it new, which is relied upon to help resolve the existing problems in the defense resource management. If we try to find this object among the direct instruments of the concept listed above we will come to the conclusion that there is no anything new. The theory has long been proven that specialization, prioritization, economies of scale, etc. are useful tools in resource management. The majority of member states form and realize their defense policies based on these and other principles on which is based the concept of smart defense. Examples can be given in various directions - from the joint acquisition of weapons and equipment, common use of infrastructure for education and training of forces to build joint forces and solving joint tasks in the security sector. Where, then, is the holder of a novelty item in the concept of smart defense. According to the author the novelty should be somewhere in the way of thinking and acting of those that define the defense policies of member states and those who implement these policies in practice. This is the main reason for the difficulties and obstacles that frequently arise when trying to implement the concept of smart defense. It appears easier for people to apply a new management tool created by other people and with proven high efficiency, rather than to change their way of thinking, behavior and decision making. Difficulties arise from the need for sharing between member states intentions for development, sensitive information, technical requirements, etc. in conditions of insufficient trust. It actually shows a familiar paradox that says the trust between partners is build in the process of cooperation but starting cooperation is possible in case of trust between partners. Evident in this direction is the role of NATO, which is to build an environment of trust and making shared interest between member states, thereby creating the conditions for applying the smart defense concept.

In summary of the above arguments can be said that under certain conditions the concept of smart defense and its practical implementations can be considered as innovation in thinking and decision making in the management of defense resources. Unambiguous synthesis answers of the top question are impossible and require an individual approach to each case.

*Corresponding author: Venelin Georgiev, Center for Security and Defense Management in the Institute on Information and Communication Technologies, Bulgarian Academy of Sciences, Bulgaria, E-mail: georgiev@defencemanagement.org

Received September 10, 2012; Accepted September 13, 2012; Published September 20, 2012

Citation: Georgiev V (2012) Is the Smart Defense Concept an Innovation? J Def Manag 2:e116. doi:10.4172/2167-0374.1000e116

Copyright: (c) 2012 Georgiev V. This is an open-access article distributed under the terms of the Creative Commons Attribution License, which permits unrestricted use, distribution, and reproduction in any medium, provided the original author and source are credited. 
The author admits that there are supporters and their arguments to prove the different hypotheses on the matter, i.e, the concept of intelligent defense is a definitely innovative approach in the management of defense resources, or that the same concept is nothing new except the very phrase. It is a proof for the complexity of the subject that makes it interesting and offers opportunities to develop and deepen the discussion. The point here is to be understood correctly that the smart defense concept is not itself a panacea and cannot meet the high expectations and to resolve issues related to the management of resources in the defense in times of austerity and reduced defense budgets. To the fore once again arise the issue of the quality of human resources, which are expected to turn into reality the smart defense concept in an innovation for the defense resource management.

\section{Submit your next manuscript and get advantages of} OMICS Group submissions

\section{Unique features:}

- User friendly/feasible website-translation of your paper to 50 world's leading languages Audio Version of published paper Digital articles to share and explore

Special features:

- 200 Open Access Journals

15,000 editorial team

21 days rapid review process

Quality and quick editorial, review and publication processing

- Indexing at PubMed (partial), Scopus, DOAJ, EBSCO, Index Copernicus and Google Scholar etc

- Sharing Option: Social Networking Enabled

- Authors, Reviewers and Editors rewarded with online Scientific Credits

Better discount for your subsequent articles

Submit your manuscript at: http://www.editorialmanager.com/pharma 